\title{
Ferrule Effect pada Manajemen Klinis Crown Lengthening Pasca Perawatan Saluran Akar
}

Miftahul Jannah ${ }^{1}$, Kosno Supriyanto ${ }^{1}$

Korespondensi: Kosno Suprianto; [skosno@yahoo.com]; Telp: 081363728674

\begin{abstract}
A case of a 27-year-old female patient presented clinically with short clinical crown due to caries and after endodontic treatment on upper right central incisor needs ferrule effect for final endodontic restoration was managed by surgical crown lengthening. To maintain a healthy periodontal-restorative interrelationship, exposure of tooth structure supragingivally becomes necessary which can be achieved by surgical crown lengthening. Biological width measured by comparing clinical and periapical radiograph. The reported case highlights the importance of through examination, proper diagnosis and the multidisciplinary approach.
\end{abstract}

Keywords: crown lengthening; biological width; ferrule effect; periodontal-restorative interrelationshi

Affiliasi penulis: ${ }^{1}$ Fakultas Kedokteran Gigi, Universitas Andalas, Padang, Sumatera Barat,Indonesia.

\section{PENDAHULUAN}

Mahkota klinis gigi adalah jarak dari margin gingival ke insisal edge atau permukaan oklusal gigi. Mahkota gigi bisa menjadi pendek jika disebabkan oleh karies subgingival, fraktur mahkota, ukuran gingival yang berlebih atau karena anatomi gigi. Salah satu prosedur yang dilakukan untuk mendapatkan mahkota klinis yang sesuai adalah dengan melakukan Crown Lengthening (CL). Menurut American Academy of Periodontolgy $(A A P)$, crown lengthening adalah prosedur untuk menambah panjang struktur mahkota supragingival untuk restoratif atau untuk tujuan estetik dengan cara memposisikan margin gingival lebih ke apikal, pembuangan tulang, atau keduanya. Hubungan antara kesehatan periodontal dan restorasi gigi sangatlah dekat dan tidak dapat dipisahkan. Restorasi gigi dapat bertahan dalam jangka waktu yang lama apabila didukung dengan kesehatan periondontal yang baik, agar gigi dapat dipertahankan. ${ }^{1,2}$

Pada umumnya, persiapan jaringan periodonsium sebelum dilakukannya perawatan restoratif pada gigi dapat dibagi menjadi dua tahap; (1) pengendalian inflamasi periodontal dengan pendekatan non bedah dan (2) bedah preprostetik periodontal, yang salah satunya adalah terapi crown lengthening. 1,2 Mahkota klinis gigi yang pendek tidak bisa dievaluasi hanya dengan inspeksi, namun harus dilakukan secara komprehensif, yang didukung dengan pemeriksaan radiografi. Jika mengandalkan pemeriksaan klinis dibutuhkan evaluasi terhadap biological width periodontal. Dengan melakukan crown lengthening, biological width yang normal dapat dipertahankan, dimana hal ini sangat penting untuk mempertahankan kesehatan jaringan periodonsium dalam jangka panjang. Dan apabila diperlukan pada tahapan fase restorasi-protesa lanjutan, crown lengthening juga dapat memfasilitasi untuk mendapatkan efek ferulle. ${ }^{1,3}$ 
Meskipun crown lengthening pada umumnya dilakukan oleh spesialis periodonsia, dokter gigi umum pada dasarnya tidak memiliki alasan untuk tidak melakukan prosedur tersebut, selama tidak melanggar zona nyamannya. Crown lengthening secara garis besar melibatkan berbagai teknik, termasuk gingivectomy atau gingivoplasty, serta pembukaan flap yang diposisikan dengan tepat dengan atau tanpa reseksi tulang. Pada kasus ini dilakukan crown lengthening pada pasien setelah perawatan endodontic dengan tujuan mendapatkan efek ferrule sebagai retensi restorasi akhir endodontik $k^{3,4}$

\section{KASUS}

Seorang perempuan berusia 27 tahun datang ke RSGMP Universitas Andalas mengeluhkan gusi bengkak pada gigi atas bagian depan. Pasien mulai menyadari gusi pada gigi atas depan bengkak sejak memakai gigi tiruan yang dibuatkan oleh tukang gigi. Terlihat bengkak dan sedikit berdarah ketika pasien melepas gigi tiruan. Pasien hanya berkumur air biasa untuk menghentikan perdarahan. Pada riwayat dental, pasien pernah ke dokter gigi untuk menambal gigi (sekitar 10 tahun yang lalu). 2 tahun yang lalu melakukan perawatan ortodonti cekat,sekarang sudah di lepas. 2 bulan yang lalu pergi ke tukang gigi untuk membuat gigi tiruan. Pasien menyikat gigi 2 kali sehari (pagi dan malam). Pasien memiliki kebiasaan mengunyah makanan 1 sisi (sebelah kiri). Pasien merupakan seorang ibu rumah tangga, tidak merokok, tidak mengkonsumsi alkohol, tidak mengkonsumsi obat-obatan apapun, namun pasien memiliki kebiasaan minum teh (setiap hari). Riwayat keluarga pasien, ayah dan ibu pasien tidak dicurigai menderita penyakit sistemik. Riwayat kesehatan umum pasien pernah dirawat di rumah sakit karena demam berdarah (10 tahun yang lalu).

Pada pemeriksaan ekstra oral tidak ditemukan adanya kelainan, namun pada pemeriksaan intra oral terdapat kalkulus supragingiva dan subgingiva, sedang, terlokalisasi pada bagian bukal posterior kanan dan kiri rahang atas, posterior bagian lingual dan anterior rahang bawah dengan indeks Oral Hygiene Index OHI 5,5 (Sedang) dan Gingival Index GI : 0,61 (Gingivitis ringan) dan RKP 55\% pada awal kunjungan. Terdapat oedema pada interdental dan servikal bagian labial dan palatal gigi 11. Kemerahan pada bagian distolabial dan palatal gigi 11, coral pink pada mesiolabial dan palatal dengan konsistensi kenyal, lunak, permukaan gingival pada gigi tersebut licin dan interdental papil membulat. Pada pemeriksaan penunjang radiografi periapikal terlihat Kehilangan struktur mahkota gigi mencapai 2/3 bagian, terdapat gambaran radiolusen berupa lesi pada bagian apikal.
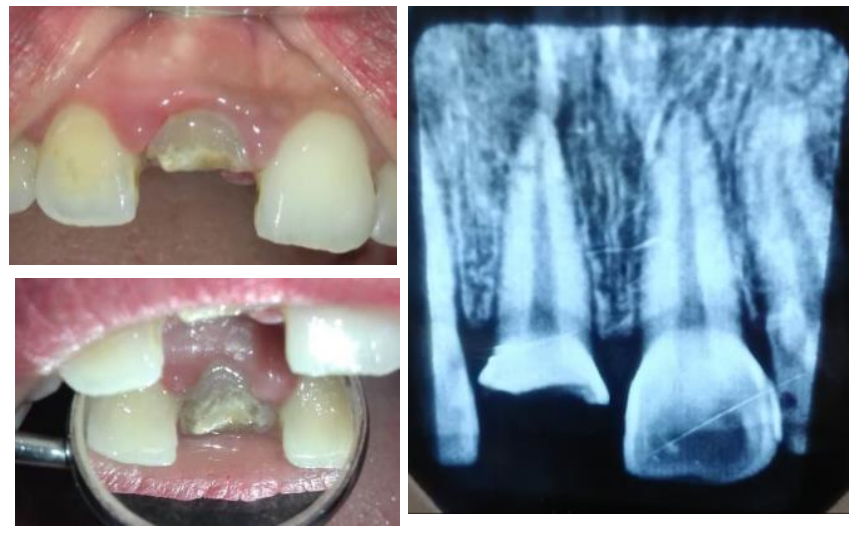

Gambar 1. Gambaran klinis dan radiografi 
Berdasarkan pemeriksaan intraoral berupa kalkulus supragingiva dan subgingiva, $\mathrm{OHI}$ sedang, serta pembesaran gingiva bagian interdental dan servikal pada gigi 11. Didapatkan diagnosa gingival enlargement yang dicurigai disebabkan oleh plak dan kalkulus, serta iritasi kronis. Sikap pasien kooperatif, prognosa baik karena tidak ada penyakit sistemik yang mempengaruhi kondisi jaringan periodontal, usia pasien masih muda (27 tahun) dan kooperatif.

Kunjungan awal sebagai terapi inisial pada pasien dilakukan kontrol plak, Scaling root planing serta edukasi pasien. Fase bedah berupa: Gingivektomi (crown lengthening) pada gigi 11 dan Perawatan saluran akar gigi 11 (sudah dikerjakan). Fase restoratif: pembuatan restorasi indirect postcore and crown pada gigi 11, pembuatan gigi tiruan untuk menggantikan gigi yang hilang. Kemudian untuk fase pemeliharaan: Evaluasi kesehatan periodontal setiap minimal 6 bulan sekali, dengan cek RKP, probing depth, ada tidaknya inflamasi gingiva dan mobilitas gigi. Kedalaman probing pada gigi 11 tersebut adalah $222 \mathrm{~mm}$ (fasial) dan $212 \mathrm{~mm}$ (palatal).

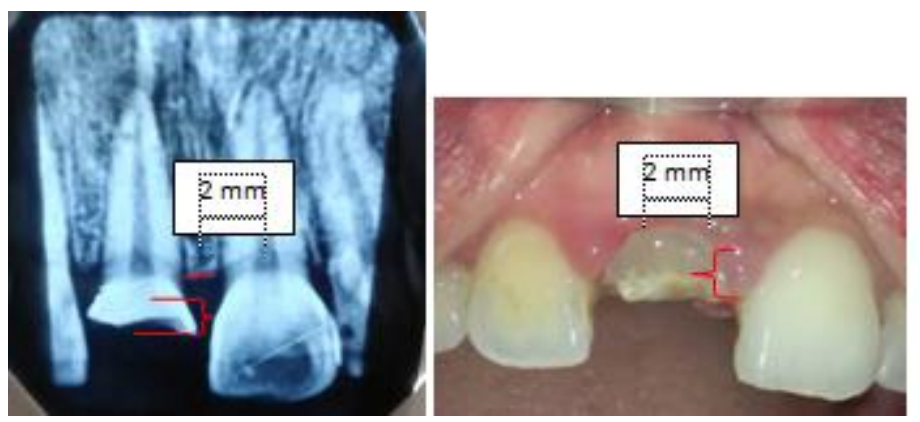

Gambar 2. Perhitungan jarak biological width gigi 11

Sebelum tindakan bedah dilakukan, operator melakukan penghitungan terhadap besar margin gingival yang akan di potong untuk mendapatkan efek ferule yang diinginkan $(1 \mathrm{~mm})$ dengan mempertimbangkan biological width gigi yang akan di restorasi nantinya. Biological width gigi pasien adalah $2 \mathrm{~mm}$, foto dibawah ini adalah proyeksi untuk perhitungan pertimbangan biological width, hal ini bertujuan untuk mempertimbangkan apakah prosedur bedah membutuhkan pembuangan tulang atau tidak, foto radiografi yang digunakan harus 1:1. Selain itu operator juga melakukan pengukuran panjang kerja saluran akar dan panjang gigi. ( panjang saluran akar: 17,5 mm dan panjang gigi $19 \mathrm{~mm}$ ).

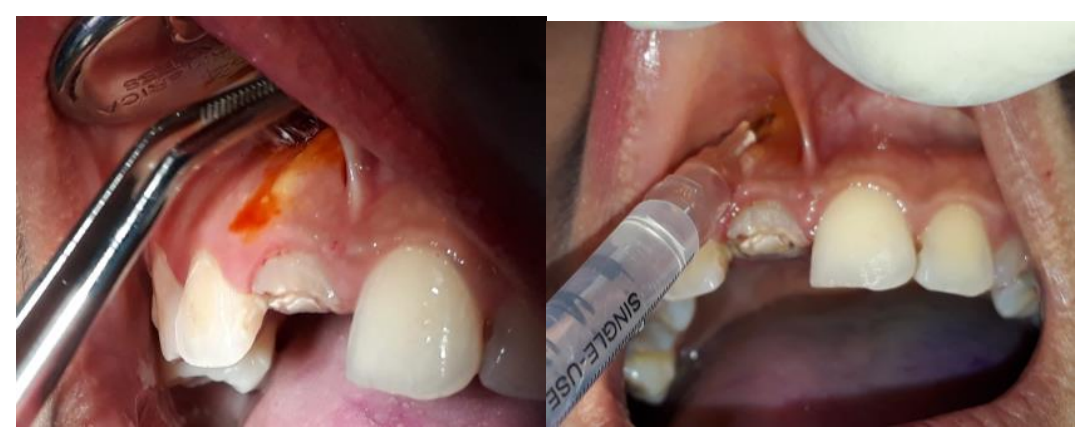

Gambar 3. Desinfeksi area kerja dan anastesi infiltrasi 
Prosedur gingivektomi dilakukan pada tanggal 7 november 2018 dengan RKP 10,34\%. Lakukan Pengukuran tekanan darah dan pengisian informed consent terlebih dahulu. Pasien menyetujui dilakukan tindakan tersebut, dengan bukti penandatanganan lembar persetujuan tindakan medis oleh pasien, saksi,dan preseptor. Hasil pengukuran tekanan darah: 110/80 $\mathrm{mmHg}$. Langkah pembedahan selanjutnya yaitu dengan melakukan desinfeksi area kerja dan sekitarnya dengan povidone iodine dan melakukan anastesi infiltrasi pada mukobukal fold dan palatal gigi 11.

Langkah berikutnya yaitu menentukan letak dasar poket dengan probe dan sonde untuk membuat bleeding point dan menentukan garis insisi menggunakan sonde dengan menyambungkan titik-titik penandaan yang dibuat sebelumya. Pembedahan dilakukan dengan mengeksisi bagian yang sudah di tandai, pemotongan bagian vestibular dilakukan menggunakan pisau kirkland, dan pada bagian interdental menggunakan pisau orban. Marginal gingiva dan gingivoplasty dirapikan menggunakan blade nomor 15 .

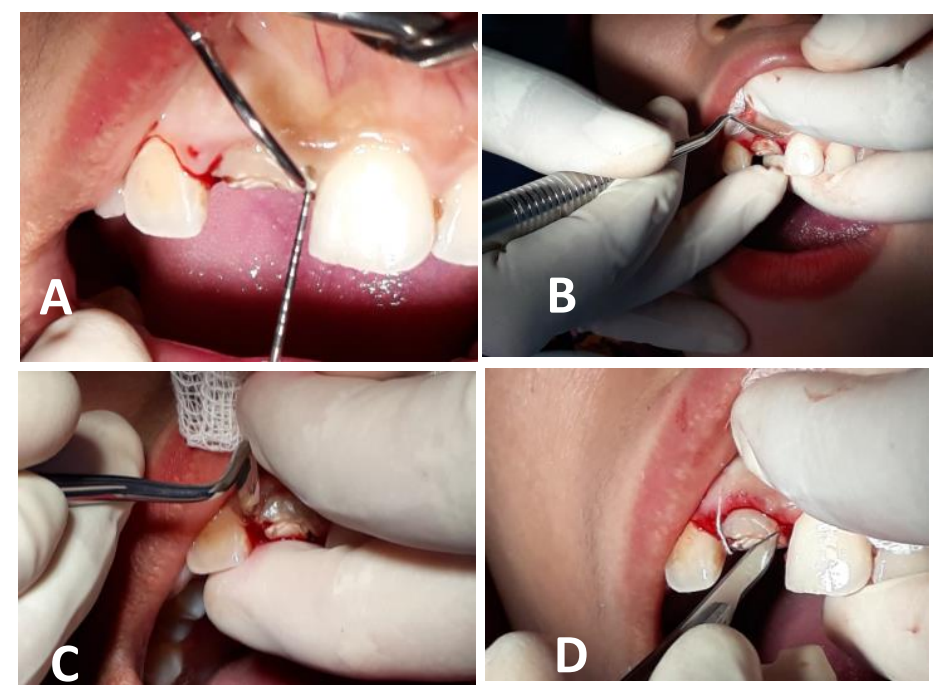

Gambar 4. A) Penentuan dasar poket; B) Eksisi bagian vestibular dengan pisau kirkland; C) Eksisi bagian interdental dengan pisau orban;

Scalling Root Planning (SRP) dilakukan secara manual untuk menyingkirkan kalkulus yang belum bisa di bersihkan pada fase inisial, lalu area opersi di irigasi dan dikeringkan. Langkah akhirnya yaitu dengan menutup daerah bekas operasi dengan peck periodontal.
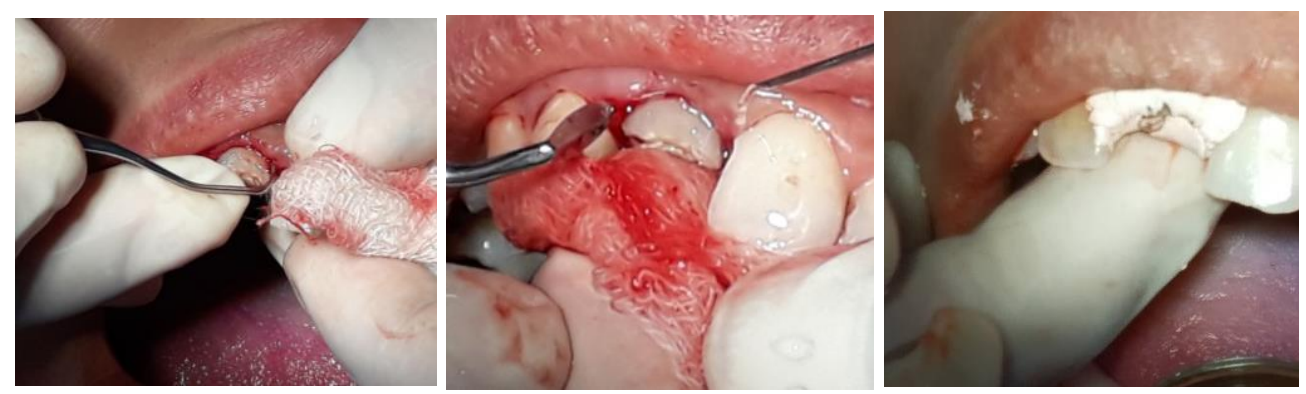

Gambar 5. A) Scaling root Planing (SRP); B) Irigasi area operasi; C) Penutupan area operasi dengan pek periodontal 

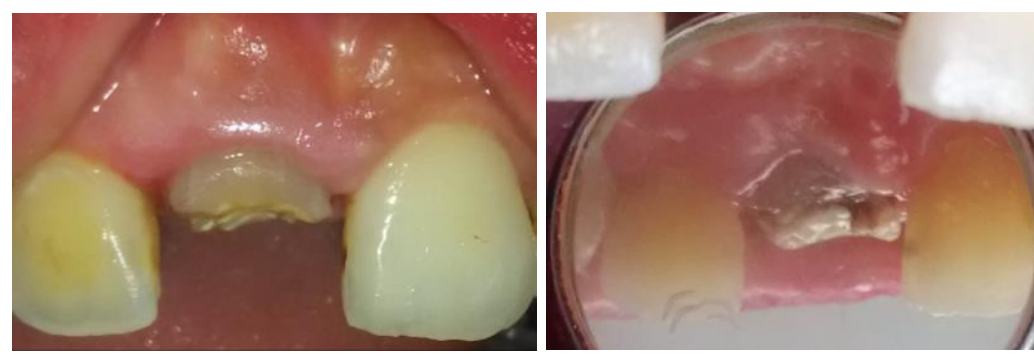

Gambar 6. Gambaran klinis bukal dan palatal setelah satu minggu pembedahan

Setelah prosedur pembedahan selesai dilakukan, pasien diresepkan obat antibiotik (caplet amoxicillin $500 \mathrm{mg}$ ) dan analgetik (caplet asam mefenamat $500 \mathrm{mg}$ ) serta obat kumur cholrhexidine $0,1 \%$ sebagai obat antibakteri dan penghilang rasa nyeri setelah pembedahan. Pasien diiinstruksikan pasca bedah, yaitu jaga $\mathrm{OH}$, gigi yang di lakukan gingivektomi tidak digunakan untuk mengunyah dahulu selama 24 jam dan hindari makanan panas dan pedas, hindari penggunaan gigi tiruan, instruksikan untuk kontrol kembali, serta jika perlu berkumur dengan obat kumur chlorheksidine (minosep). Setelah 1 minggu dan 1 bulan perawatan dilakukan pengecekan kembali pada daerah operasi sebagai evaluasi terhadap perawatan.
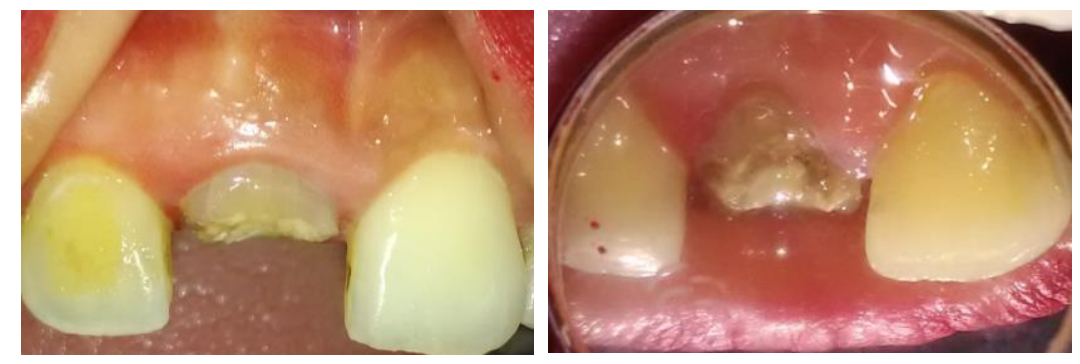

Gambar 7. Gambaran klinis bukal dan palatal setelah satu bulan pembedahan

\section{DISKUSI}

Pada pemeriksaan objektif pasien saat datang ke rumah sakit gigi dan mulut terdapat pembesaran pada margin gingival gigi 11. Gigi tersebut sebelumnya telah dilakukan perawatan saluran akar dan akan dibuatkan restorasi indirect berupa post core \& crown. Oleh karena gingiva pada gigi tersebut menutupi sebagian besar mahkota gigi, dan ingin mendapatkan ferrule effect restorasi indirect nanti, berdasarkan pertimbangan-pertimbangan klinis, diputuskan gigi 11 akan dilakukan gingivektomi berupa crown lengthening (tanpa pembuangan tulang alveolar) yang didahului oleh terapi fase 1 yaitu scaling dan root planning, DHE, control plak untuk persiapan terapi periodontal selanjutnya. Tujuan dilakukan crown lengthening pada kasus ini adalah untuk menambah panjang mahkota klinis gigi dan untuk mendapatkan efek ferrule yang diperlukan nantinya untuk restorasi indirect gigi 11 pasien, yaitu sebesar $1 \mathrm{~mm}$.

Crown lengthening merupakan suatu perawatan periodontal dengan beberapa indikasi seperti untuk kebutuhan restoratif, menambah panjang mahkota klinis gigi. mengakses karies subgingiva, dan menghasilkan "ferrule" untuk restorasi serta untuk merelokasi margin restorasi yang melewati biological 
Fakultas Kedokteran Gigi Universitas Andalas

Jalan Perintis Kemerdekaan No. 77 Padang, Sumatera Barat

Web: adj.fkg.unand.ac.id Email: adj@dent.unand.ac.id

width. Crown lengthening dikategorikan sebagai pembedahan dengan tujuan estetik atau

fungsional.Tujuan "fungsional" berhubungan dengan pemaparan karies subgingiva, fraktur atau keduanya.Sedangkan tujuan

estetika, umumnya berhubungan dengan gigi anterior, dimana mahkota klinis pasien terlihat pendek. Pada praktiknya, dokter gigi dapat mengeksisi jaringan atau dengan memposisikan kembali jaringan lunak lebih ke apikal dari sebelumnya. ${ }^{6,7,8}$

Pada kasus ini pemotongan dilakukan sebanyak $2 \mathrm{~mm}$ dari margin gingiva pada bagian mesiolabial dan distolabial, serta $1 \mathrm{~mm}$ pada bagian labial dan palatal gigi 11 untuk mencapai visibilitas yang diinginkan untuk proses crown lengthening tanpa pembuangan tulang (berdasarkan perhitungan pada rontgen periapikal gigi 11 pasien, bilogical width mencukupi, yaitu sebesar $2 \mathrm{~mm}$ ), penutupan luka dilakukan dengan periodontal pack pada gigi tersebut. Pasien diinstruksikan untuk tidak menggunakan gigi tiruan sampai 1 minggu pasca pembedahan.

Penutupan jaringan luka dengan periodontal pack akan melindungi luka dari iritasi selama proses pengunyahan. Pada fase awal terjadi inflamasi singkat dan diikuti migrasi sel epitel dari tepi luka ke daerah bekas eksisi setelah 12-24 jam pasca bedah. Sel akan menutupi luka dalam waktu 7-11 hari,. Epitelisasi permukaan pada umumnya selesai setelah 5-14 hari. Vasodilatasi dan vaskularisasi mulai berkurang setelah hari ke-4 penyembuhan dan tampak hampir normal pada hari ke-16. Proses keratinisasi terjadi setelah 2-3 minggu. Pembentukan perlekatan epitel yang baru berlangsung selama 4 minggu. Repair epitelselesai sekitar 4 minggu dan repair jaringan ikat selesai sekitar 7 minggu pasca bedah. 6 minggu pasca bedah gingiva tampak sehat, berwarna merah muda, dan kenyal. Kebersihan mulut yang baik sangat diperlukan selama proses pemulihan. ${ }^{9,11}$.

Pasien datang untuk kontrol 1 minggu setelah crown lengthening (15 November 2018), pasien datang dengan kondisi pak periodontal sudah lepas (pack periodontal sudah lepas pada hari ke 4 setelah pembedahan). Pasien tidak memiliki keluhan, dilakukan irigasi dengan aquades pada gigi 11, pemeriksaan bekas luka, rekam kontrol plak (15\%). Tanda-tanda inflamasi sudah berkurang, hal ini dikarenakan masih terjadinya proses epitelisasi (terjadi pada hari ke 5-14), kontur gingiva bagus dengan tepi gingiva tajam, konsistensi kenyal. Hasil pemeriksaan klinis menunjukkan bahwa penyembuhan yang terjadi 1 minggu pasca bedah telah terjadi regenerasi jaringan, perbaikan kontur gingiva pada daerah yang dilakukan bedah, dan penurunan peradangan pada gingiva (peradangan gingiva akan sembuh sempurna pada minggu ke-3 pasca bedah). ${ }^{1,9,10}$

Selanjutnya pasien datang untuk kontrol II (1 bulan pasca bedah) 7 Desember 2018, dari pemeriksaan subjektif pasien tidak memiliki keluhan. dilakukan pemeriksaan pada RKP $(3,8 \%)$ dan probing depth, serta periksa kondisi gingiva. Hasil pemeriksaan klinis secara umum menunjukkan kondisi jaringan gingival secara umum normal/ sehat, gingiva berwarna merah muda, konsistensi kenyal dengan adanya stipling. Namun gingival bagian distopalatal 11 terlihat sedikit memerah kembali. teori menyatakan bahwa rekurensi pasca bedah dapat terjadi akibat adanya iritasi lokal residu (sisa iritasi lokal), faktor sistemik atau keturunan. ${ }^{1}$

Faktor lokal seperti food impaction, overhanging tepi restorasi, tekanan protesa yang berlebih serta kontrol plak yang tidak adekuat. Dalam kasus ini pasien tidak memiliki penyakit sistemik dan keturunan, sehingga hal tersebut diduga akibat tekanan yang ditimbulkan oleh sayap gigi tiruan yang dibuat oleh tukang 
gigi. Pasien menggunakan kembali gigi tiruan yang dibuatkan tukang gigi untuk alasan estetik. Pada kunjungan ini operator memeriksa sayap gigi tiruan yang dipasang, dan mengurangi ketebalan sayap bagian palatal gigi tiruan tersebut. Pemasangan restorasi akhir (indirect) dari gigi 11 pasca perawatan saluran akar (dilakukan setelah 3 sampai 6 bulan pasca tindakan, terutama pada restorasi yang memerlukan estetik yang tinggi). Hal ini dikarenakan free gingival margin memerlukan waktu kurang lebih 3 bulan untuk mencapai posisi vertikalnya yang tepat pasca tindakan bedah. ${ }^{1,2}$

Penyembuhan setelah tindakan bedah harus diikuti dengan program pemeliharaan oral hygiene secara adekuat. Kontrol plak yang tidak optimal menyebabkan terjadinya penumpukan bakteri plak supragingiva yang menimbulkan keradangan pada gingiva didekatnya. Dalam mencapai terapi kedokteran gigi komprehensif yang berhasil, kesehatan periodontal adalah suatu prasyarat yang penting. Kesiapan jaringan periodontal perlu dipersiapkan untuk tercapainya tujuan terapi terapeutik jangka panjang. 1,11,10

\section{SIMPULAN}

Dalam mencapai terapi kedokteran gigi komprehensif yang berhasil, kesehatan periodontal adalah suatu prasyarat yang penting. Kesiapan jaringan periodontal perlu dipersiapkan untuk tercapainya tujuan terapi terapeutik jangka panjang. Pada kasus karies dan atau fraktur mahkota gigi dapat dipertahankan dengan perawatan terapi bedah periodontal; crown lengthening untuk mengekspos struktur gigi yang tertutup jaringan lunak, dan dengan demikian dapat memfasilitasi terapi restoratif-endodontik nantinya. Terapi akan sukses apabila terdapat kerja sama yang baik antara multidisiplin ilmu (dalam hal ini ilmu bagian periodontologi dan endodontik) dan antara pasien dengan dokter gigi.

\section{KEPUSTAKAAN}

1. Newman MG, Takei HH. Carranza's Clinical Periodontolgy 9th Edition. United states of America. 2012, pp. 749-750.

2. Ardakani, M, Khalilian, Zahra, Azade. A Review of the Crown Lengthening Surgery; the Basic Concepts. British Journal of Medicine and Medical Research. 2016; 13(3): 1-7.

3. Nugala, Babitha. Biologic width and its importance in periodontal and restorative dentistry. J Conserv Dent. 2012 Jan-Mar; 15(1): 12-17.

4. Cunliffe J, Grey N. Crown lengthening surgery-indications and techniques. Dental Update, 2008; 35(1): 29-30,2,4-5.

5. Rateitschak, Klaus H, Herbert F. Wolf. Color Atlas of Dental Medicine Periodontology. 3rd revised and expanded edition. Thiemme. 2005.

6. Gupta,G, Ramesh, Nishan, Udit. Crown Lengthening Procedures- A Review Article. Journal of Dental and Medical Sciences. 2015: vol. 14 (4).

7. Hempton, Timothy J. et al. Contemporary Crown-Lengthening Therapy. The Journal of the American Dental Association, Vol. 141(6): pp. 647 - 655.

8. Andriani, Ika. Treatment Gingival Enlargement by Gingivectomy. Mutiara Medika, 2009; 9(1): 69-73.

9. Suryono, A. Electrosurgery pada gingivektomi dan gingivoplasti pembesaran gingiva pasca perawatan ortodonsia. Majalah Kedokteran, 2008; 5(1): 50-58. 
10. Ruhadi Iwan, Aini Izzatul. Kekambuhan gingivitis hiperplasia setelah gingivektomi. Maj Ked Gigi (Dent. J.), Vol. 38: pp. 108-111.

11. Djais Arni Irwaty, hasan Hasmawati. Perawatan bedah periodontal pada pasien hipertensi disertai pembesaran gingiva dan abses periodontal (laporan kasus). Makassar Dent J, 2016; 5(3): 102-104.

12. Stankiewicz, N, Wilson. The Ferrule Effect: a Literature Review. International Endodontic Journal, 2002; 35: 575-581. 